and cognitive abilities of children with Williams syndrome (WMS). Contrary to the book's authors, your reviewer claims that "children with Williams syndrome have a barely measurable general intelligence" but "an exquisite mastery of syntax and vocabulary", although they are "unable to understand even the most immediate implications of their admirably constructed sentences".

Based on our own extensive research on WMS in English and Italian, we disagree with your reviewer. First, intelligence is certainly testable in WMS. In older children, the average performance IQ is around 60 , and many score much higher. By the age of 8-10 years, children with WMS are typically functioning at a mental age of 5-6, an age at which normally developing children display sophisticated vocabulary and complex grammar.

Second, syntax is far from perfect in WMS. In younger children, lexical and grammatical development are delayed; in older children, difficulties and errors persist. Overall levels of syntax never exceed mental age.

Third, comprehension abilities in WMS are often puzzling, but they are much more sophisticated than PiattelliPalmarini implies. Individuals with WMS are extremely interesting for research on language, cognition and social functions, because they display an unusual profile of strengths and weaknesses that may be linked to the genetic alterations responsible for this syndrome. But they are not language savants, and do not provide evidence for intact language in the absence of measurable intelligence.

In short, contrary to your reviewer, we believe that Karmiloff and KarmiloffSmith 'got it right'.

Elizabeth Bates ${ }^{\star}$, Helen Tager-Flusberg $\dagger$, Stefano Vicarił, Virginia Volterra $\$$

${ }^{*}$ Center for Research in Language 0526, University of California, San Diego, 9500 Gilman Drive, La Jolla, California 92093, USA

$\dagger$ Laboratory of Developmental Cognitive Neuroscience, Department of Anatomy and Neurobiology, Boston University School of Medicine, 715 Albany Street, Boston, Massachusetts 02118-2526, USA $¥$ Servizio di Neurologia e Riabilitazione, IRCCS, Ospedale Pediatrico Bambino Gesù, Lungomare Guglielmo Marconi 36, I-00058, Santa Marinella, Rome, Italy

\$Istituto di Psicologia, CNR, Viale Marx 15, 00137 Rome, Italy

\section{Concerns highlight need to make faster decisions}

Sir - Your News story "Venture capital concerns academics" (Nature 413, 95; 2001), on the involvement of the
University of California, San Francisco (UCSF) with the Burrill venture fund, suggests a plan hatched by investors and university officials to exploit our faculty without our consent.

The conflicts for faculty and students resulting from university-industry collaborations have been well documented in, for example, The Business-Higher Education Forum's Working Together, Creating Knowledge: The UniversityIndustry Research Collaboration Initiative (American Council on Education, Washington; 2001. http://www.acenet.edu/ bookstore/index.cfm?pubID=230). It would be a pity if articles such as your News story derailed the recent improvements in relations between universities and industries by artificially setting academic scientists against those marketing their discoveries.

The lofty 'bench-to-bedside' goal we aspire to requires that scientists facilitate the transfer of their ideas into the commercial world. At UCSF we scientists, of our own volition, submit about 150 disclosures a year to our Office of Technology. Far too few of these disclosures result in useful products. A committee I chaired identified several contributing factors, including lack of funding for proof-of-principle research and for intellectual-property costs, lack of business acumen among our faculty, and cumbersome procedures. To speed up the process, we developed a non-restrictive agreement with Burrill that we hope will unclog the pipeline with no loss of faculty autonomy or of Burrill's autonomy to set up similar agreements with others.

The agreement introduced no significant changes in the way UCSF operates and required no faculty input. Nonetheless, as a public institution we are especially sensitive to public perception, and so our proposal was offered for comment to several advisory groups, including the Academic Senate, the official voice of the UCSF faculty. Some members of the senate felt that two months was not sufficient time to identify any potential conflicts of interest. It was their dissatisfaction that was reported in your News story. (And as this correspondence goes to press, the proposal seems increasingly unlikely to come to fruition).

You have nicely illustrated a real conflict of interest in industry-academic interactions. Industry needs a hierarchical structure that allows rapid decisions. Universities have a diffuse decisionmaking structure that can be slowed to glacial speeds because of lack of faculty time and diversity of opinion. If university research is truly to benefit society we need to find ways to accommodate faculty decision-making processes to the honest needs of our industrial counterparts. Regis Kelly

Executive Vice Chancellor, UCSF, Department of Biochemistry \& Biophysics, University of California, San Francisco, California 94143, USA

\section{Sound basis for research}

Sir - Your News story "Fears for basic science as Bush backs use of investment criteria" (Nature 413, 5; 2001) expresses concerns over the fate of research funding and policy under the Bush administration, owing to the establishment of researchand-development performance criteria. The Bush administration is indeed examining explicit criteria for federal investment in research according to its President's Management Agenda.

This initiative was prompted by two excellent reports by the Committee on Science, Engineering, and Public Policy (COSEPUP) - Evaluating Federal Research Programs: Research and the Government Performance and Results Act (1999; see http://books.nap.edu/html/gpra) and Implementing the Government Performance and Results Act for Research (2001; see http://books.nap.edu/html/gpra2) — and by other observations from the scientific community, such as the US House of Representatives Committee on Science 1998 report Unlocking Our Future: Toward a New National Science Policy (http://www.house. gov/science/science_policy_report.htm). The administration's efforts will start with applied research programmes, and apply the lessons learned to the evaluation of basic science. The administration supports explicit criteria for the quality, relevance and appropriate federal role of projects, rather than basing funding levels on vague anecdotes and previous-year funding levels.

The administration does not believe all basic research should be done by industry, nor are we developing criteria in isolation with merely 'green-eyeshade' views of research investments. We fully understand the difficulties of applying performance measures to basic research programmes, but this does not exclude good management and high performance. We have had extensive consultations with COSEPUP, the Office of Science and Technology Policy, members of Congress and their staff, and other leading researchers. These have provided useful insights that we are incorporating into our work.

The National Academy of Sciences has laid a foundation for us. We invite the scientific community to continue to work with us as we tackle the difficult task of implementing these sound ideas.

Mitchell E. Daniels, Jr

Director, Office of Management and Budget, 725

17th Street NW, Washington, DC 20009, USA 